\title{
Literatura negra e/ou afro-brasileira: uma tentativa de conceituação
}

\section{Black and/or Afro-Brazilian literature: an attempt of conceptualization}

\author{
Magdalena Walczuk \\ Universidade de Varsóvia \\ madalena.walczuk@gmail.com
}

\begin{abstract}
The article aims to discuss the concept of black and/or Afro-Brazilian literature. It summarizes different approaches to the definition of Afro-Brazilian literature elaborated both by critics and its authors, taking in consideration the elements such as authorship, point of view, thematic content, language / aesthetic or target reader. Presenting briefly the presence (as object and subject) and the image of the black population in the Brazilian literary canon, the article discusses the way it has been deconstructed and transgressed by Afro-Brazilian authors.
\end{abstract}

Keywords: black literature, Afro-Brazilian literature, Afrocentricity, Afro-Brazilian identity, decolonial perspective

\section{INTRODUÇÃO}

A literatura é uma forma socialmente valorizada de discurso, da qual, por longos tempos da história, só se serviram grupos muito restritos, principalmente os pertencentes às classes altas, detentoras do capital cultural suficiente para ingressar na esfera da cultura erudita. É também um espaço em que se refletem várias tensões da ordem social, cultural ou mesmo econômico-política, existentes dentro de uma sociedade e em que diferentes vozes sociais podem ser (des)legitimadas, ouvidas e reconhecidas ou marginalizadas e apagadas. Nesse universo opera, pois, o poder simbólico definido por Bourdieu (1989) e reproduzem-se relações entre os dominan- 
tes e dominados. A nossa abordagem, tal como a maioria dos estudos sobre a literatura negra a que nos referimos, assume uma perspectiva decolonial, principalmente no sentido de identificar o viés étnico-racial e eurocêntrico na formação do cânone nacional (colonialidade do saber), assim como no de perceber a literatura negra como uma tentativa de falar a partir de um lugar epistêmico subalterno, com vistas a elaborar um projeto literário contra-hegemônico (Bernardino-Costa \& Grosfoguel, 2016). Neste artigo procuraremos discutir estas questões em contexto da presença dos afrodescendentes na literatura brasileira (tanto como tema, como voz autoral) e do surgimento da literatura afro-brasileira, a qual passamos a conceitualizar na segunda parte do artigo.

A voz da população afrodescendente, que atualmente constitui um pouco mais da metade da sociedade brasileira, é pouco representada na literatura brasileira, em particular na pertencente ao cânone nacional. É, sem dúvida, uma das consequências nefastas do sistema colonial e escravocrata que marcou profundamente a formação da sociedade brasileira e cujos frutos - em forma de desigualdades sociais, econômicas e culturais, acompanhados por preconceitos e/ou discriminação de cunho étnicoracial - são colhidos até hoje. A população afrodescendente explorada como mão de obra escrava e tocada pelos processos de exclusão e opressão mesmo após a Abolição, foi marginalizada também nos projetos da nacionalidade brasileira, na história oficial do país e, consequentemente, na literatura nacional.

Ao referir-se a imagem do negro veiculada pela grande parte da literatura brasileira, Fonseca (2014) afirma:

A representação do negro (...) agrega valores e visões forjados no âmbito da escravidão, interessados em afirmar a inferioridade dos negros ou a sua condição instintiva - propensos à submissão e/ou à violência. Tais visões ficam evidentes na caracterização de personagens negras infantilizadas ou imbecilizadas, que reproduzem a condição subalterna em que os africanos escravizados viviam na sociedade brasileira (p. 255).

A ideologia de branqueamento difundida na sociedade brasileira e proveniente dos mitos da superioridade da raça branca e civilização europeia, encontrou sua tradução no espaço literário. Decorria nele o mesmo processo de branqueamento simbológico: dos poucos escritores afrodescendentes que passaram pela literatura brasileira, vários foram "branqueados" pela história, através da omissão ou camuflagem das suas origens étnico-raciais. Eles mesmos, aliás, por vezes assumiam uma estratégia de dissimulação, construindo sua obra de acordo com os modelos dominantes e eurocêntricos, sem que a sua afrodescendência tivesse qualquer influência no seu projeto literário e levasse a uma tentativa mais séria de abordar a temática negra de uma forma mais rica e complexa (Duarte, 2013, p. 146).

Mesmo que a literatura do século XX traga uma presença relativamente maior do negro na literatura, a sua representação ainda está muito longe de retratar a real complexidade da vivência negra, tanto menos problematizar as questões como 
discriminação racial, desigualdades sociais ou a resistência cultural e luta política da população afro-brasileira. As pesquisas revelam que o perfil do escritor brasileiro permanece o de homem branco, de classe média, heterossexual, morador de grande cidade. Dos romances publicados nas maiores editoras no Brasil entre 1965-2014, o número de autores negros, assim como dos personagens negros (colocados predominantemente nos papéis secundários, subalternos e reproduzindo clichês de doméstica, bandido ou prostituta), gira em torno de 7\% (Massuela, 2018).

Não cabe nos limites deste trabalho uma análise mais completa da representação do negro no cânone literário brasileiro. Para aprofundar o assunto, recomendamos os estudos de Bernd (1988), Dalcastagnè (2008), Duarte (2008; 2013), Duarte \& Fonseca (2014), Fonseca (2000), Mérian (2008), Proença Filho (1997), que apresentam um panorama extenso da presença negra na literatura brasileira.

\section{A LITERATURA NEGRA NO BRASIL}

É difícil estabelecer com precisão o momento em que a literatura negra instalase no cenário literário do Brasil como um fenômeno ao mesmo tempo "por dentro e por fora da literatura brasileira", como diz Ianni (1988, p. 91). O sociólogo refere-se ao seu surgimento desta maneira:

A literatura negra é um imaginário que se forma, articula e transforma no curso do tempo. Não surge de um momento para outro, nem é autônoma desde o primeiro instante. Sua história está assinalada por autores, obras, temas, invenções literárias. É um imaginário que se articula aqui e ali, conforme o diálogo de autores, obras, temas, invenções literárias. É um movimento, um devir, no sentido de que se forma e transforma (p. 91).

Como o resultado desse processo duradouro e não-linear constitui-se aos poucos o perfil do que hoje denominamos de literatura negra ou afro-brasileira ${ }^{1}$ e todo um sistema significativo particular. Ela compartilha com a literatura brasileira a mesma língua e, praticamente, as mesmas formas, gêneros e processos de expressão, mas o seu foco de interesse e a missão são distintas. De acordo com Duarte (2008), ela visa a desenvolver um projeto suplementar (no sentido derridiano) do trabalhado pela literatura brasileira canônica: "o de edificar, no âmbito da cultura letrada produzida pelos afrodescendentes, uma escritura que seja não apenas a sua expressão enquanto sujeitos de cultura e de arte, mas que aponte o etnocentrismo que os exclui do mundo das letras e da própria civilização". Disso provinha seu caráter muitas vezes marginal, pois "fundado na diferença que questiona e abala a trajetória progressiva e linear da historiografia literária canônica” (p. 22). A literatura negra,

\footnotetext{
${ }^{1}$ Mais adiante discutiremos a questão de várias denominações dadas a este tipo de literatura.
} 
revertendo as imagens fixas e lugares comuns destinados ao negro no campo literário, estabelece-se, portanto, como uma espécie de contraliteratura que "caminha na contramão do cânone", abrindo espaço para vozes até então pouco ouvidas e para uma "força criativa adormecida porque sempre reprimida" (Fonseca, 2008, p. 57, 59).

As vozes negras que destoavam dos padrões dominantes apareciam aqui e ali na história da literatura brasileira. Como precursores dessa vertente literária, apontamse até obras e autores do século XIX. Um deles é o poeta Luís Gama, quem nas suas Trovas Burlescas subverte as formas e imagens tradicionais, invocando a "musa de Guiné", cor-de-azeviche, apresentando a si próprio como um "Orfeu de carapinha" e atingindo com a sua sátira a sociedade escravagista (Bernd, 1988, pp. 51-55). Quanto à prosa, destaca-se a figura do escritor mulato Lima Barreto, cuja obra ficcionista, retratando a realidade social urbana e suburbana do Rio de Janeiro, denuncia o preconceito e as injustiças sociais cometidos em relação aos negros. Em 1859, foi também publicado o primeiro romance abolicionista brasileiro Úrsula, escrito por uma autora afrodescendente Maria Firmina dos Reis (Fonseca, 2008, p. 258).

Nas primeiras décadas do século XX podemos notar um esforço intensificado da população afrodescendente em procurar meios e espaços para manifestar suas ideias e formar opinião através da linguagem escrita. Nas décadas 1920-1940, surge a chamada imprensa negra que aborda temas variados diretamente ligados à população negra - as revistas Menelik, Alfinete, Clarim da Alvorada, A Voz da Raça em São Paulo e $O$ Quilombo no Rio de Janeiro. A última foi dirigida por Abdias de Nascimento, figura central da militância negra do Brasil e criador do Teatro Experimental do Negro, iniciativa que visou a ampliação do espaço cultural para o negro e estimulou a produção das peças teatrais voltadas à temática negra e que valorizavam sua herança cultural ao par que discutiam questões atuais e pertinentes à comunidade negra.

Na mesma época começam a ser publicadas as obras poéticas de autores negros tais como Solano Trindade, Oswaldo de Camargo, Domício Proença Filho, ou Lino Guedes, fundamentais na procura de novas formas de expressão da subjetividade negra. A década de 1970 pode ser considerada o momento da consolidação da literatura negra. Surgem então coletivos de escritores negros, com frequência aliados à luta política e todo o movimento cultural e identitário negro da época Quilombhoje em São Paulo, Negrícia no Rio de Janeiro ou Palmares em Porto Alegre. As iniciativas editoriais independentes desse tipo conseguem ampliar significativamente o espaço para as produções literárias dos autores afrodescendentes. Muitos autores afro-brasileiros, hoje já estabelecidos no mundo literário, como Cuti ou Conceição Evaristo, deram os seus primeiros passos como escritores dentro daqueles coletivos. Merece destaque a série Cadernos Negros, uma das iniciativas publicitárias mais duradouras e importantes no que toca à difusão e ao fortalecimento da literatura afro-brasileira no país, inaugurada no ano 1978. Desde então, 
a cena literária afro-brasileira tem-se ampliado e diversificado significativamente. Seria difícil resumir aqui as produções afro-brasileiras dignas de atenção, pois, além de se tratar de uma escolha necessariamente subjetiva, ela fugiria um tanto do foco principal do nosso artigo. Recomendamos que o leitor procure referências nos artigos citados na bibliografia, em particular a obra de quatro volumes Literatura e Afrodescendência no Brasil: antologia crítica (Duarte \& Fonseca, 2014) que é a coletânea dos textos afro-brasileiros provavelmente mais completa das até então publicadas.

\section{LITERATURA “INCOLOR”, NEGRA OU AFRO-BRASILEIRA?}

A partir da década de 1970 surgem primeiras tentativas de conceitualizar este novo fenômeno literário, emergente nas margens do mercado. Os estudos de Ianni (1988) e Bernd (1988), citados aqui, constituíram fundamentos para a definição da literatura negra e permanecem referências básicas até hoje. No artigo recorrermos também a textos importantes de Proença Filho (2004), Duarte (2008) e Souza (2008), além de trazer contribuições muito ricas de próprios escritores afro-brasileiros, reunidos em forma de entrevista na antologia referida acima (Duarte \& Fonseca, 2014). Tentaremos resumir as principais ideias acerca do conceito da literatura negra reunidas nestes textos e pô-las em diálogo.

Ao propormos uma tentativa de definição da literatura negra, logo no início deparamos com a pergunta se a categorização epidérmica da literatura é viável num país multiétnico e pluricultural como o Brasil, em que estabelecer uma "linha de cor" é "ato temerário, já que essa é capaz de variar de acordo com a condição social do indivíduo, o local e mesmo a situação", pois "inexistem no país regras fixas ou moldes de descendência biológica aceitos de forma consensual" (Schwarcz, 1998, p. 182). Torna-se logo necessário discutir se a cor da pele do autor ou/e a temática negra permitem nos mesmo classificar um texto como afro-brasileiro ou há também outros fatores que entram em jogo? Nos próximos parágrafos, discutiremos estas questões mais detalhadamente, seguindo a ordem de cinco fatores constitutivos proposta por Duarte (2008).

Referindo-se à mestiçagem étnica e cultural, Bernd (1992) nota que ela não impede a existência, ao mesmo tempo, de uma identidade / consciência negra. A emergência da consciência do que significa ser negro no Brasil, está há algum tempo em curso e reflete-se num discurso literário diferenciador que pode ser identificado em uma série de textos, entre os quais existe uma certa articulação dada por "um modo negro de ver e de sentir o mundo" (p. 13). Referindo-se à questão da legitimidade da expressão "literatura negra", a autora observa também um certo perigo em rotular os autores ou os textos e fechá-los em "guetos literários", no entanto, considera igualmente nefasto rejeitar ou desprezar as reivindicações de 
próprios autores que se autodenominam dessa forma, pois "o fato de assumirem essa nomeação, conscientemente, pode ser interpretado como um sinal de que os negros estão querendo criar a si mesmos e que uma das etapas deste processo seria justamente a de particularizar sua escritura, dando-lhe feição própria" (1988, p. 21).

O suposto "risco terminológico", assinalado no ensaio de Proença Filho (2004), que seria implícito na expressão "literatura negra", aparentemente valorizadora, pode "converter-se em risco de acabar fazendo o jogo de preconceito velado" (p. 193), é também descartado por maioria dos autores e teóricos. O escritor Cuti afirma que mesmo que exista o risco, ele tem que ser corrido, pois as cautelas desse tipo, de fato, "abrigam no fundo a domesticação ideológica costumeira que se fazia com os africanos no Brasil e que continua a ser feita com afrodescendência". Segundo o autor, não nomear, seria jogar a literatura brasileira na invisibilidade (Duarte \& Fonseca, 2014, p. 46). Outra escritora negra, Alzira Rufino, aponta que a rotulação da literatura permite reconhecer a contribuição negra num campo que tradicionalmente não lhes pertencia: "É necessário que as pessoas entendam que o negro não é só cerveja, pagode, suor e futebol. Ele sapateia muito bem, goleia com perícia, mas precisa estar nas mesas da decisão e nessas mesas eu coloco a literatura" (p. 101).

Souza (2008), por sua vez, nota que a rejeição de quaisquer qualificativos de etnia ou gênero que enfatizam o lugar de onde falam os escritores, é uma posição que tenta omitir alguns fatos presentes na literatura, pois a ausência de um qualificativo explícito ratifica, de fato, o que as convenções sociais estabeleceram como hegemônico e, ao mesmo tempo, universal e que acaba excluindo todos os recursos expressivos e estilísticos "impuros" (p. 51).

Mas qual seria a denominação mais apropriada para esse tipo de literatura? Cada uma das denominações que aparecem - literatura negra / afro-brasileira / afrodescendente / negro-brasileira - tem suas particularidades e gera discussões entre teóricos e os próprios autores. Cuti defende a palavra "negro" por ser mais "polissêmica e contundente" e trazer em si uma rejeição à ideologia de branqueamento, pois, a categoria "afro-brasileiro" pode incluir mesmo os que recusam a identidade negra. Além disso, o termo "negro" é associado a toda a história da resistência e militância negra e recorrer a outros, na sua opinião, só enfraquece o poder da própria palavra e seu peso histórico e político. Ele considera o termo "afro-brasileiro" um termo "forjado no gabinete", "vazio de vida" e "apaziguado de conflitos", já que ele não estimula os brancos e mestiços a refletirem acerca das relações raciais e de toda a história de exploração e discriminação racialmente motivada. Os negros devem reapropriar-se da palavra negro e insistir em carregá-la positivamente (Duarte \& Fonseca, 2014, pp. 60-63).

O termo "literatura afro-brasileira" é, por sua vez, defendido por outro escritor, um dos integrantes do grupo Quilombhoje e fundadores de Cadernos Negros, 
Márcio Barbosa. Ele aceita as duas denominações, no entanto, destaca que o termo "afro" remete mais à ancestralidade e à cultura, enquanto o termo "negro" tem uma conotação mais racial e biológica. No Brasil, pois, a questão do negro relaciona-se, principalmente, pela cor, enquanto pelo afro-brasileiro entende-se o descendente de africanos e isso por si só já evoca toda a questão cultural por trás e a identificação dos indivíduos com o legado africano. Diferentemente de Cuti, ele acha que o termo "afro-brasileiro" contraria a miscigenação branqueadora, na medida em que permite incluir os afrodescendentes, por exemplo mulatos, que não se consideram negros, mas reconhecem-se na afrodescendência, e como tal é um termo mais abrangente (Duarte \& Fonseca, 2014, p. 80).

De acordo com Bernd, no século XXI consolidou-se o uso dos termos "literatura afro-brasileira" e "afrodescendente" que substituiu o termo "negro" para evitar a epidermização do conceito, ou em outras palavras, a definição de uma expressão artística pela cor da pele dos autores. Mesmo analisando os títulos de antologias e obras teórico-críticas é possível notar uma crescente tendência a favor do termo "literatura afro-brasileira", no entanto é de sublinhar que as duas denominações coexistem e funcionam como sinônimas, dependendo do posicionamento do escritor ou teórico a preferência por uma ou outra $(2010$, p. 32). Neste artigo optamos por usar os dois termos alternadamente.

\section{A AUTORIA E O PONTO DE VISTA}

A pergunta central e, ao mesmo tempo, a mais polêmica no debate conceitual é a questão da autoria da literatura negra. As opiniões acerca desta questão polarizam-se entre a postura mais radical que aceita como autores dessa literatura apenas os negros, valoriza portanto antes de tudo os fatores fenotípicos e biográficos, e a postura mais inclusiva que, tendo em conta as dificuldades na própria definição quem é negro no Brasil e procurando abarcar também as identidades fraturadas resultantes do processo miscigenador, enfatiza a perspetiva do autor que conscientemente assume uma ótica, que podemos chamar de afrocentrada.

A primeira postura é defendida, entre outros, por escritor Oswaldo de Camargo quem acredita que a literatura negra se realiza "quando o autor, voltando-se para a sua pessoa e sua vida como autor de origem negra, escreve em torno dessa experiência específica" (Duarte \& Fonseca, 2014, p. 40). As produções de autores não-negros, tais como Jorge Amado ou Jorge de Lima, que têm o negro como tema principal, poderiam ser classificadas apenas como negristas. Isso não apenas por conta da autoria, mas, antes de tudo, pela maneira de abordar a temática que não sai muito longe dos padrões dominantes na literatura brasileira tout court e acaba reforçando alguns estereótipos, como o da "mulata assanhada", presente na obra amadiana. No 
entanto, Camargo realça que a origem do autor não é a única condição para considerar sua escrita como negra: "Um negro pode criar uma literatura sem marcas, nos moldes daquela canonizada já há séculos por grandes autores, sem tropeçar na sua identidade, que o autor negro procura pôr no texto como uma personagem" (p. 40). Deste modo, ele confirma a posição defendida por vários autores e teóricos de que a autoria há que estar conjugada intimamente ao ponto de vista específico.

Cuti também parece compartilhar a mesma convicção. Embora ponha enfoque no ponto de vista e na importância de o autor ter o leitor negro como horizonte na hora de criar texto, ou seja, embora não exclua radicalmente o escritor branco, ao mesmo tempo, expressa uma profunda descrença na possibilidade de um autor branco conseguir se "despojar de brancura" e atingir o nível de empatia que o permitisse escrever dentro de uma subjetividade negra, que Cuti considera praticamente intransferível. $\mathrm{O}$ escritor sublinha que desconhece na literatura brasileira "um escritor branco que escreveu na primeira pessoa de um negro" (Duarte \& Fonseca, 2014, pp. 46-49).

As escritoras Esmeralda Ribeiro e Conceição Evaristo reforçam esta intransferência da experiência alegada por Cuti. Ribeiro sublinha a dificuldade em descrever o preconceito e discriminação por alguém que nunca os sentiu na própria pele (Duarte \& Fonseca, 2014, p. 92). Enquanto Evaristo coloca uma pergunta retórica "Será que alguém escreve o texto do outro" (p. 115)? Para caraterizar o seu fazer literário a escritora recorre muitas vezes ao neologismo criado por ela mesma escrevivência, explicando que as identidades múltiplas que a diferenciam - a de mulher, cidadã brasileira, negra, oriunda das classes populares, mãe, viúva, etc. consciente e inconscientemente, orientam a escrita dela, conduzindo o ponto de vista que habita o seu texto (pp. 114-115).

Abdias de Nascimento apresenta uma postura mais aberta, reconhecendo que os textos de autores não-negros também podem convergir com a literatura afro-brasileira, desde quando assumirem uma subjetividade negra. Esta opinião inserir-se-ia na noção da afrocentricidade elaborada por professor norte-americano Molefi K. Asante. Dentro dessa perspetiva, não é só a cor da pele que importa, mas o lugar de onde o indivíduo (neste caso o autor) enxerga o mundo em volta, por isso mesmo sendo branco, ele pode ser afrocentrista (Duarte \& Fonseca, 2014, p. 20).

Duarte (2008), recorrendo a mesma ideia da afrocentricidade, passa a definir esta ótica singular, presente na literatura negra, do modo seguinte:

Assim, compreendemos a adoção de uma visão de mundo própria e distinta da do branco, sobretudo do branco racista, como superação da cópia de modelos europeus e de toda a assimilação cultural imposta como única via de expressão. Ao superar o discurso do colonizador em seus matizes passados e presentes, a perspectiva da negritude configura-se enquanto discurso da diferença e atua como elo importante dessa cadeia discursiva que irá configurar a afrodescendência na literatura brasileira (p. 18). 
Percebe-se que tal visão afasta-nos da redução sociológica, que interpreta uma obra a partir dos fatores externos (cor da pele, origem étnica ou social do autor), em vez disso nos convida a compreender a autoria "na condição de traduzida em constante discursiva integrada à materialidade da construção literária" (Duarte, 2008 , p. 15). O pesquisador destaca que a adoção desta ótica, permite descobrir dimensões até então pouco exploradas nas obras dos autores que não explicitam a sua afrodescendência de uma forma direta, tal como por exemplo Cruz e Souza ou Machado de Assis. Nas obras deles o universo negro aparece fragmentado, pouco estruturado e, para usar as palavras de Ianni (1988): “implícito, subjacente, decantado" (p. 92). A reinterpretação da sua produção a partir de ângulos distintos dos consagrados pela crítica, permite "resgatar" esses autores como fundadores da literatura negra no Brasil. Assim, Machado de Assis se tornaria "clássico duas vezes", já que a sua sátira que atinge os setores dominantes, deixa percebê-lo como defensor da causa negra. Segundo Ianni, Machado "abre, em grande estilo, a visão paródica do mundo burguês, a partir da perspectiva crítica mais profunda do negro escravo ou livre" (p. 95). Ao mesmo tempo que os subalternos parecem gozar de maior compreensão e benevolência nos olhos do escritor.

É interessante observar que "o poeta dos escravos" Castro Alves, via regra, não é mencionado entre os fundadores da literatura negra e isso não apenas por conta da cor da pele, mas acima de tudo pela maneira como ele aborda a temática negra nos seus poemas. Mesmo defendendo a causa da libertação dos negros, ele mantém uma postura distanciada, sempre tratando o negro como "o Outro" e não saindo na sua crítica muito além dos limites aceitáveis pela classe dominante, nem da praxe literária romântica (Bernd, 1988, pp. 58-61).

Qual então seria o fator determinante, a partir do qual podemos falar em literatura negra e não apenas na literatura sobre o negro? Segundo Bernd, esse demarcador de fronteiras, em particular no caso do discurso poético, seria a emergência de um sujeito-de-enunciação que se afirma e se quer negro, "revelador de um processo de conscientização de ser negro entre os brancos" e que "um certo modo negro de ver e sentir o mundo" (1988, p. 22, 48). A estudiosa passa a caraterizar esse eu lírico afrodescendente do modo seguinte: "Passando de outro a eu, o negro assume na poesia sua própria fala e conta a história de seu ponto de vista. Em outras palavras: esse eu representa uma tentativa de dar voz ao marginal, de contrapor-se aos estereótipos (negativos e positivos) de uma literatura brasileira legitimada pelas instâncias de consagração" (p. 50). Esse eu-que-se-quer-negro marcaria também o momento da passagem do estado de alienação ao estado da conscientização, como também da reapropriação da imagem sua e da sua coletividade. $\mathrm{O}$ autor torna-se, então, uma espécie da porta-voz da sua comunidade e a reúne, ao mesmo tempo, em torno de valores comuns, ajudando na construção de uma identidade positivamente afirmada, individual e coletiva (pp. 77-79). 


\section{TEMÁTICA}

Não é surpreendente que, ao ampliar o espaço no campo literário em que o negro foi marginalizado ou teve imagem distorcida, os autores afrodescendentes tentam preencher esses vazios e passam a tratar, principalmente, da temática negra, ou seja, falar do sujeito afrodescendente tanto no plano do indivíduo, como o da coletividade, abordando todo o universo humano, social, cultural e artístico compartilhado pela população negra (Ianni, 1988, p. 92). No entanto, é de destacar, que esta temática não é única e obrigatória e não se deveria transformar em uma "camisa de força" ou autocensura prévia que limite a criatividade dos autores negros (Duarte, 2008, p. 14).

A temática abraçada pela literatura negra é muito diversificada, no entanto, podemos destacar nela algumas linhas temáticas que aparecem com maior frequência dentro dessa vertente literária. Grande parte das obras discute o lugar do negro na sociedade brasileira atual, a marginalização e escassez de oportunidades, a luta contra discriminação, a vivência diária numa sociedade marcada pela desigualdade, violência e pelo preconceito racial. Várias obras tornam-se de fato uma forma de denúncia dos dramas vividos pela população negra.

O que nos parece particularmente relevante é, porém, o fato de a literatura afrobrasileira abordar as relações afetivas e familiares dos homens e mulheres negros, que são praticamente inexistentes no caso dos poucos personagens que aparecem na literatura brasileira dominante. Convertendo essa visão reducionista, a literatura negra retrata os negros como seres humanos completos, dotados de toda uma gama de emoções, sentimentos, dores e problemas existenciais. Há também uma procura pelo resgate da maternidade e paternidade negra, tema completamente marginalizado e distorcido pela literatura brasileira e em que se reflete visivelmente a nefasta herança escravista em forma da desestruturação da família negra.

Outro eixo temático recorrente é o resgate da história do negro brasileiro, que visa trazer à luz vários fatos, heróis e momentos marcantes na resistência do povo negro, apagados ou mascarados pela história oficial o que corresponderia à "construção da epopeia negra" nas palavras de Bernd (1988, p. 80). Além de revelar a opressão vivida pelo negro, mesmo depois da Abolição, os autores desconstroem a imagem do passado histórico pacífico, da escravidão "benigna" e do escravo negro submisso, reconstituindo a memória das lutas e revoltas.

Dessa maneira, tanto no campo de histórico, como, do modo parecido, em domínio social, cultural ou ainda literário é construído todo o sistema de representações e referências positivas para toda a comunidade negra (Bernd, 1988, p. 99). O negro, deixa de representar apenas um elemento passivo ou uma mera contribuição ao universo construído pelo branco, mas torna-se um agente ativo, cuja participação na construção do Brasil foi fundamental e igualmente valiosa. O riquíssimo universo cultural afro-brasileiro é explorado em vários textos, incluindo todo 
o repertório de elementos rituais e religiosos que evocam a herança africana. Os autores pretendem resgatar e preservar na escrita a memória ancestral, todo o tesouro de mitos e lendas e do imaginário afro-brasileiro, do legado cultural que atravessou o Atlântico, transmitido predominantemente pela oralidade. Os laços com a África mítica, berço comum de todos os africanos dispersos na diáspora, são cantados em tal como nos versos do poema de Ademiro Alves-Sacolinha: "África mãe, Brasil filho, / O leite do mundo habitou suas tetas" (Ribeiro \& Barbosa, 2008, p. 113).

É importante destacar que, quando esses elementos culturais e valores compartilhados pela comunidade negra aparecem na literatura afro-brasileira, não são mais tratados como algo de fora, como algo "exótico" ou através de um viés folclorizante, mas como uma parte integral de todo o universo negro, descrito através de um olhar afrocêntrico (Duarte \& Fonseca, 2014, pp. 50-52).

\section{LINGUAGEM}

Ao se tratar da literatura, ou seja uma construção discursiva em que é a dimensão estética é fundamental, torna-se, logo, necessário refletir acerca da linguagem que diferencie a literatura negra de textos pertencentes à literatura dominante. Segundo Duarte (2008), a afro-brasilidade de um texto:

(...) tornar-se-á visível já a partir de uma discursividade que ressalta ritmos, entonações, opções vocabulares e, mesmo, toda uma semântica própria, empenhada muitas vezes num trabalho de ressignificação que contraria sentidos hegemônicos na língua. Isto porque, bem o sabemos, não há linguagem inocente, nem signo sem ideologia (p. 18).

As palavras-chave tornam-se aqui a desconstrução e a transgressão. É preciso romper com a linguagem e as formas tradicionais e buscar novas formas de expressão, inventar uma nova linguagem "negramente colorida", tanto no nível do vocabulário quanto no dos símbolos: "proceder uma desconstrução do mundo nomeado pelo branco e a erigir sua própria cosmogonia" (Bernd, 1988, p. 22). Cuti chama a atenção para o esforço de transgredir os limites do próprio idioma que veicula os valores e a estética branca, em que o modelo branco, ocidental, masculino, cristão foi entronizado como universal. O negro, "minando pés de barro" de uma suposta universalidade, precisa reinventar a si mesmo, tendo grande cautela para não cair - consciente ou inconscientemente - nas armadilhas preconceituosas e estereotípicas, tão arraigadas na própria linguagem e nos modelos estabelecidos pela tradição literária (Duarte \& Fonseca, 2014, pp. 56-57).

Como nota Bernd (1988), o próprio conceito da literatura negra emerge de uma caraterística dos signos que permanecem em um constante movimento de rotação-ressig-

\footnotetext{
${ }^{2}$ Referência à expressão usada por Camargo (Duarte \& Fonseca, 2014, p. 42).
} 
nificação, onde "os signos que nos exilam podem vir a ser os mesmos que nos constituem na dimensão humana", assim o signo "negro" pode "remeter à ofensa e à humilhação, mas também pode ser assumido com orgulho" (pp. 95-96). A literatura negra traz a possibilidade de reverter valores e sentidos pejorativos atrelados ao negro, entre outros os relativos ao corpo, cujas marcas negras, tais como cor da pele, formato do nariz, lábios grossos ou cabelo pixaim, carregam uma conotação negativa, reforçada pelos padrões de beleza brancos difundidos pela indústria e mídia. Um dos recursos preferidos de autores negros, é a apropriação paródica que "utiliza a linguagem do preconceito contra o preconceito", apoderando-se assim do discurso opressor (Duarte, 2008, p. 17).

A inovação no nível da linguagem que os textos da literatura negra oferecem dáse também pela utilização do vocabulário pertencente ao universo cultural e religioso afro-brasileiro, assim como de uma ritmicidade e entonações particulares ou em outras palavras, uma certa sonoridade herdada da África e preservada no ritmo dos tambores ou cantares (Duarte, 2008, p. 20). Um exemplo disso pode ser o refrão que, repetido várias vezes seguidas, dá ritmo ao todo o poema Batuque de Carlos de Assumpção: "Tambor que bate / Batuque batuque bate" (2008, pp. 28-30).

\section{PÚBLICO LEITOR}

A constituição do seu próprio público leitor - "marcado pela diferença cultural e pelo anseio de afirmação identitária" - é o quinto componente dos destacados por Duarte (2008) na hora de definir o projeto literário afro-brasileiro, avaliado por ele como um tanto utópico. Os obstáculos são muitos, começando pelos fatores da ordem mesmo econômica que dificultam o acesso aos livros, passando pelo desafio de implantar o gosto e hábito de leitura entre o público tradicionalmente afastado desse tipo de produção, e chegando à concorrência da parte dos meios eletrônicos de comunicação (pp. 20-21). No entanto, notemos que os mesmos podem se tornar aliados na difusão das obras dos autores afro-brasileiros nos sites da literatura ou nas redes sociais. Dada a dificuldade em publicar e promover seus textos no mercado literário mainstream, os escritores negros aproveitam amplamente as possibilidades oferecidas pelo ambiente virtual, conquistando seu espaço em blogs, vídeo blogs, sites dedicados à temática afro-brasileira, ganhando uma maior visibilidade e possibilidade do contato direto com o público e divulgação e venda das suas produções.

A preocupação de formar um público leitor específico que se reconhecesse nas obras e integrasse em torno delas, buscando valorização da identidade e cultura negras acompanhou os escritores negros já mesmo na época antes da popularização da Internet. Eles iam com seus livros na mão, em busca de leitores, a vários espaços periféricos. A organização de saraus, rodas de leitura e lançamentos em locais por vezes mais inusitados da periferia, tem se tornado uma prática comum e muito 
eficiente na formação tanto do público como de futuros escritores, realizada muitas vezes no âmbito de uma movimentação cultural mais abrangente, por exemplo a do hip-hop. Os escritores conseguem quebrar, ao mesmo tempo, a imagem da literatura como algo hermético e inalcançável.

Cuti sublinha a importância de o autor negro saber que o seu texto será lido por um leitor negro capaz de entender e se identificar com ele até nas questões mais íntimas e sutis. Esse "leitor negro ideal" que o escritor tem como destinatário na hora de criar, traria uma "liberação fantástica" e levaria ao "destravamento do processo criativo" que não precisa ser mais "um exercício de malabarismos metafóricos para se esconder", ou seja, descarta uma espécie de autocensura imposta quando se tem o leitor branco como horizonte (Duarte \& Fonseca, 2014, p. 54). Ele afirma que graças às reações e aos comentários desse público que, em muitos casos, não tinha antes contato com a arte literária, os escritores negros ousam experimentar na linguagem e meios expressivos, (re)pensando a estética do seu trabalho (p. 58).

\section{CONCLUSÕES}

A literatura afro-brasileira mostra-se como um espaço em que emerge uma força criativa adormecida e as construções literárias que dela nascem ainda continuam à procura de sua autodefinição. Podemos afirmar, recorrendo às palavras de Chiampi que esta literatura "constrói a sua identidade no próprio processo discursivo da sua indagação” (Bernd, 1988, p. 12). Ao efetuar a desmontagem das práticas literárias tradicionais e dominantes, apoderando-se do direito de falar sobre si mesmos a partir da perspectiva afrocêntrica e construir o seu próprio sistema de representações, os escritores negros, propõem uma abordagem nova, capaz de arejar as estruturas e práticas discursivas da literatura brasileira como um todo. $\mathrm{O}$ potencial revolucionário desta literatura promete que ela possa tornar-se muito mais do que uma produção surgida na margem do campo literário brasileiro dominante. Enquanto os teóricos esforçam-se para definir e descrever esse fenômeno literário em processo de formação, os escritores continuam criando, pois, como nota Cuti, felizmente eles não precisam de definição para produzir (p. 46). 


\section{BIBLIOGRAFIA}

Alves, A. (2008). A noite te convida. In E. Ribeiro \& M. Barbosa (Eds.), Cadernos Negros: três décadas. Ensaios, poemas, contos (pp. 113-114). São Paulo: Quilombhoje, SEPPIR.

Assumpção, C. de (2008). Batuque. In Cadernos Negros: os melhores poemas (pp. 28-30). São Paulo: Quilombhoje.

Bernardino-Costa, J. \& Grosfoguel, R. (2016). Decolonialidade e perspectiva negra. Sociedade e Estado, 31 (1), 15-24, https://dx.doi.org/10.1590/S0102-69922016000100002.

Bernd, Z. (1988). Introdução à literatura negra. São Paulo: Brasiliense.

Bernd, Z. (2010). Da voz à letra: itinerários da literatura afro-brasileira. Via Atlântica, 18, 29-41, https://doi.org/10.11606/va.v0i18.50737.

Bernd, Z. (Eds.) (1992). Poesia negra brasileira: antologia. Porto Alegre: Ed. AGE, IEL, IGEL.

Bourdieu, P. (1989). O poder simbólico. Rio de Janeiro: Bertrand Brasil.

Dalcastagnè, R. (2008). Entre silêncios e estereótipos: relações raciais na literatura brasileira contemporânea. Estudos de Literatura Brasileira Contemporânea, 31, 87-110. Retrieved from http://periodicos.unb.br/index.php/estudos/article/view/9434.

Duarte de Assis, E. (2008). Literatura afro-brasileira: um conceito em construção. Estudos de Literatura Brasileira Contemporânea, 31, 11-23. Retrieved from http://www.redalyc.org/ articulo.oa?id=323127095001.

Duarte de Assis, E. (2013). O negro na literatura brasileira. Navegações - Ensaios, 6 (2), 146-153. Retrieved from http://revistaseletronicas.pucrs.br/ojs/index.php/navegacoes/article/view/16787.

Duarte de Assis, E. \& Soares Fonseca, M.N. (2014). Literatura e afrodescendência no Brasil: antologia crítica (vol. 4). Belo Horizinte: Ed. UFMG.

Ianni, O. (1988). Literatura e consciência. Revista Do Instituto De Estudos Brasileiros, 28, 91-99, https://doi.org/10.11606/issn.2316-901X.v0i28p91-99.

Massuela, A. (2018). Quem é e sobre o que escreve o autor brasileiro. Entrevista com Profa. Regina Dalcastagnè. Revista Cult, 231. Retrieved from https://revistacult.uol.com.br/home/ quem-e-e-sobre-o-que-escreve-o-autor-brasileiro/.

Mérian, J.-Y. (2008). O negro na literatura brasileira versus uma literatura afro-brasileira: mito e literatura. Navegações, 1 (1), 50-60. Retrieved from http://revistaseletronicas.pucrs.br/ojs/ index.php/navegacoes/article/viewFile/3684/2834.

Proença Filho, D. (2004). A trajetória do negro na literatura brasileira. Estudos Avançados, 18 (50), 161-193, https://dx.doi.org/10.1590/S0103-40142004000100017.

Schwarcz, L.M. (1998). Nem preto nem branco, muito pelo contrário: cor e raça na intimidade. In L.M. Schwarcz, História da vida privada no Brasil; contrastes da intimidade contemporânea (pp. 173-244). São Paulo: Companhia das Letras.

Soares Fonseca, M.N. (2000). Visibilidade e ocultação da diferença: imagens do negro na cultura brasileira. In M.N. Soares Fonseca (Ed.), Brasil afro-brasileiro. Belo Horizonte: Autêntica (pp. 87-115).

Soares Fonseca, M.N. (2008). Cadernos Negros: 30 anos de literatura em compasso de resistência”. In E. Ribeiro \& M. Barbosa (Eds.), Cadernos Negros: três décadas. Ensaios, poemas, contos (pp. 57-67). São Paulo: Quilomhoje, SEPPIR.

Souza, F. (2008). 30 anos de leitura. In E. Ribeiro \& M. Barbosa (Eds.), Cadernos Negros: três décadas. Ensaios, poemas, contos (pp. 43-56). São Paulo: Quilombhoje, SEPPIR. 